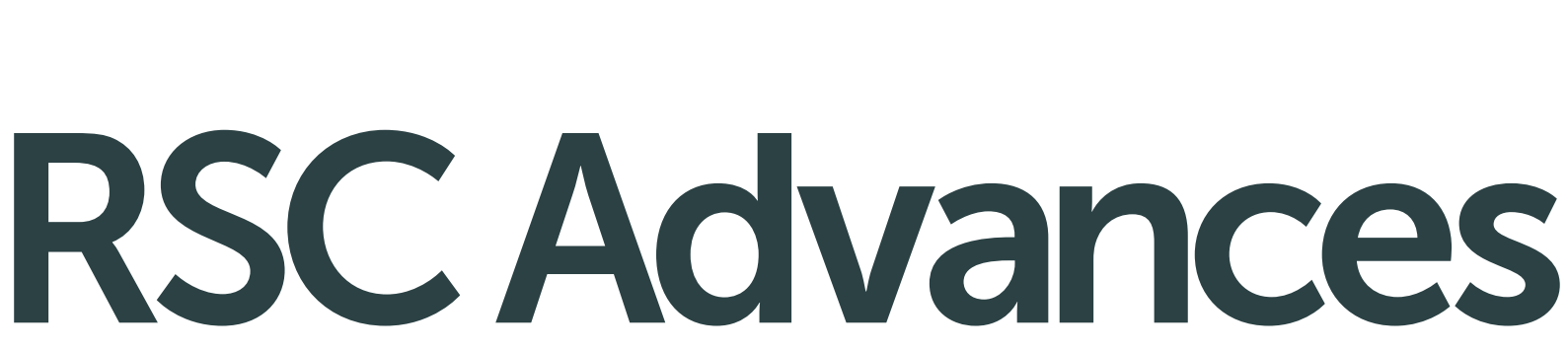

This article can be cited before page numbers have been issued, to do this please use: Y. Ren, J. Zhang,

Q. Xu, Z. Chen, D. Yang, B. Wang and Z. Jiang, RSC Adv., 2014, DOI: 10.1039/C4RA02109F.

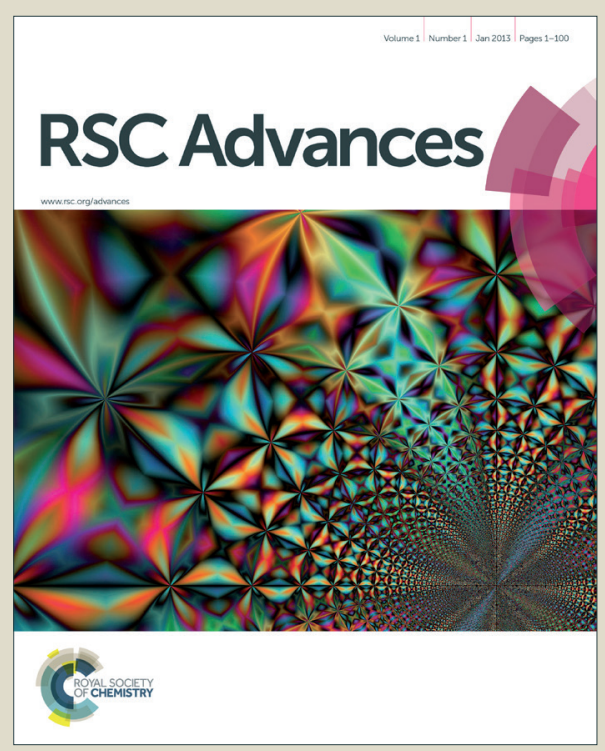

This is an Accepted Manuscript, which has been through the Royal Society of Chemistry peer review process and has been accepted for publication.

Accepted Manuscripts are published online shortly after acceptance, before technical editing, formatting and proof reading. Using this free service, authors can make their results available to the community, in citable form, before we publish the edited article. This Accepted Manuscript will be replaced by the edited, formatted and paginated article as soon as this is available.

You can find more information about Accepted Manuscripts in the Information for Authors.

Please note that technical editing may introduce minor changes to the text and/or graphics, which may alter content. The journal's standard Terms \& Conditions and the Ethical guidelines still apply. In no event shall the Royal Society of Chemistry be held responsible for any errors or omissions in this Accepted Manuscript or any consequences arising from the use of any information it contains. 


\title{
Biomass-derived Three-dimensional Porous N-doped Carbonaceous Aerogel for Efficient Supercapacitor Electrodes
}

\author{
Yumei Ren ${ }^{\mathrm{a}}$, Jianmin Zhang ${ }^{\mathrm{a}}$, Qun Xu ${ }^{\mathrm{a} *}$, Zhimin Chen ${ }^{\mathrm{a}}$, Daoyuan Yang ${ }^{\mathrm{a}}$, Bo Wang ${ }^{\mathrm{a}}$, Zheng Jiang ${ }^{\mathrm{a}, \mathrm{b}^{*}}$ \\ Received (in XXX, XXX) Xth XXXXXXXXX 20XX, Accepted Xth XXXXXXXXX 20XX \\ ${ }_{5}$ DOI: $10.1039 / \mathbf{b 0 0 0 0 0 0 x}$
}

\begin{abstract}
Functionalized carbonaceous materials with hierarchical structure and developed porosity are highly desired in energy storage and conversion fields. In this work, a facile and scalable hydrothermal methodology was established to synthesise three-dimensional (3D) N-doped carbonaceous aerogels using biomass-based starting materials and polypyrrole as $\mathrm{N}$-source. The effect of different calcination 10 temperatures on the structural properties, type and content of $\mathrm{N}$-species and electrochemical performance of the 3D N-doped carbonaceous aerogels were uncovered. Thanks to the combinatorial effect of the appropriate $\mathrm{N}$ content and porous structure, the obtained samples exhibited excellent electrochemical performance, in particular, an outstanding specific capacitance of $281.0 \mathrm{~F} \mathrm{~g}^{-1}$ achieved on the sample calcined at $600{ }^{\circ} \mathrm{C}$. This methodology offers a new fabrication strategy to prepare nanoscale carbonaceous 15 materials with desirable morphology and hierarchical architecture with great potentials for the applications in energy fields.
\end{abstract}

\section{Introduction}

The development of electrochemical systems with high power and energy densities for sustainable energy storage has been 20 regarded as one of the critical solutions to resolve the global concerns on fossil fuels depletion and environment deterioration. ${ }^{1,2}$ Among various advanced electrical energy storage systems, supercapacitors have attracted tremendous interest as energy storage devices due to their higher power 25 density and longer cycle life than batteries and conventional capacitors. ${ }^{3-5}$ Once high quality electrodes may be fabricated, supercapacitor would be an attractive alternative or supplement to batteries in a variety of applications, especially for mobile electrical systems that requires high power densities and fast 30 transient response.

Carbon-based materials are extensively used as supercapacitor electrodes because of their environmental friendliness, low cost and excellent physicochemical properties, such as fine electric conductivity, long cycle lifetime and 35 intrinsic stability etc. ${ }^{4,6-11}$ Among the diverse carbon materials, nanoscaled carbons with three-dimensional (3D) porous architecture are more plausible for high specific capacitance due to their high specific surface area and developed porosity that provide a continuous electron pathway to facilitate ion transport 40 by shortening diffusion pathways and ensure excellent electrical contact. ${ }^{12-16}$ To date, porous carbons are usually prepared via template-directed syntheses using either hard template or soft template. ${ }^{13,17}$ More recently, great effort has been attempted to prepare novel porous carbonaceous materials through ${ }_{45}$ hydrothermal carbonization (HTC) of biomass, a low-cost, and naturally abundant sustainable carbon resource. ${ }^{18-22}$ Such HTC synthesised carbonaceous materials may inherit the monolithic architecture of the original biomass or take special morphologies, such as nanospheres, nanofibers and so on. Despite such porous so carbons possess large surface area, tunable pore structure, good mechanical stability and conductivity, their surfaces are either hydrophobic or short of specific active sites, and thus limit their widespread practical applications. ${ }^{23,24}$

Heteroatom-doping represents an effective strategy to tune ss the intrinsic surface properties of the carbonaceous electrode as to energy conversion and storage. ${ }^{25-27}$ Various non-metal elements, including N, S, P, etc., have ever been successfully doped into porous carbon materials with enhanced energy storage,$^{28}$ while $\mathrm{N}$ is more plausible dopant owing to its unique 60 electronic properties originated from the conjugation lone-pair electrons of $\mathrm{N}$ and graphitic $\pi$-bonds. ${ }^{11,26,29,30}$ In addition, the substituted $\mathrm{N}$ that partially replaces $\mathrm{C}$ atoms and destroys carbon frameworks, would create more active sites and defects with enhanced electron density and electron donating properties. ${ }^{31-33}$ ${ }_{65}$ Usually, N-doping in carbon materials can be realized either directly using nitrogen-containing precursors or post-treatment of synthetic porous carbons. ${ }^{4,31,34-36}$ The post-treatment methodologies often induce only surface functionalization. ${ }^{34,35}$ The N-precursor route can preserve $\mathrm{N}$ at a relatively large 70 content and homogeneously incorporate $\mathrm{N}$ into the bulk carbon materials in the simple preparation procedure $^{33,36}$ More importantly, the doped $\mathrm{N}$ in the carbon network can stay steadily under a harsh working condition. ${ }^{11,38}$ The N-enriched conducting polymers are often adopted to porous carbon electrodes to 75 enhance their electrochemical performance. ${ }^{11,39}$ Carbonization of $\mathrm{N}$-containing aromatic polymer materials such as polyacrylonitrile (PAN), ${ }^{35,40}$ polypyrrole (PPy), ${ }^{10,24,41}$ polyaniline 
(PANI) ${ }^{41}$ melamine resin, ${ }^{42}$ have been convinced efficient strategy to prepare N-containing carbon nanomaterials. Among the precursors used for N-doped carbons, PPy stands out for its high nitrogen content and carbon yield. ${ }^{10,43}$

We here report a facile HTC process for synthesis of $3 \mathrm{D} \mathrm{N}$ doped porous carbonaceous aerogels, in which hydrothermal carbonization of watermelon were conducted prior to nitriding it using PPy precursor that served as N-source as well as supplementary carbon source. In this work, PPy was prepared by 10 using the hydrothermal process with the aid of $\mathrm{FeCl}_{3}$ as the oxidant, which is simple and convenient. The methodology manifested a facile route to tailor the surface areas and pore structures of the obtained products. The dependence of the electrodes' supercapacity, $\mathrm{N}$ species and content on the annealing 15 temperature were thoroughly investigated.

\section{Experimental}

Materials: All the chemicals were in analytic grade used without further purification. Pyrrole $\left(\mathrm{C}_{4} \mathrm{H}_{5} \mathrm{~N}, \mathrm{MW}\right.$ : 67.09), Iron ( $\square$ ) chloride anhydrous $\left(\mathrm{FeCl}_{3}\right.$, purity: $\left.\geqq 99 \%\right)$ Potassium hydroxide 20 (KOH, purity: $\geqq 85 \%$ ), dehydrated alcohol $\left(\mathrm{CH}_{3} \mathrm{CH}_{2} \mathrm{OH}\right.$, purity: $\geqq 99.7 \%$ ), deionized water, and watermelon as the carbon resource.

Preparation of Carbonaceous Hydrogels and Aerogels: The carbonaceous hydrogel (CG) was prepared by a simple 25 hydrothermal process directly from the soft tissue biomass of watermelon. Watermelon was first cut into the appropriate volume and then put into the corresponding Teflon-lined stainless steel autoclave. And the autoclave was heated to $180{ }^{\circ} \mathrm{C}$ for $12 \mathrm{~h}$. The obtained carbonaceous hydrogel monoliths were 30 washed by deionized water and dehydrate alcohol (the volume ratio is $1: 1)$ to remove the soluble impurities. Then corresponding carbonaceous aerogel (CA) was obtained by freeze-drying at $-42{ }^{\circ} \mathrm{C}$ for 2 hours, followed by drying at $60{ }^{\circ} \mathrm{C}$ for 12 hours.

${ }_{35}$ Preparation of $\mathbf{N}$-doped carbonaceous aerogel composite materials: All the chemicals were analytic grade reagents used as received without further purification. The $\mathrm{N}$-doped carbonaceous aerogel composite materials were synthesized under hydrothermal conditions. Polypyrrole (PPy) was prepared 40 with the aid of $\mathrm{FeCl}_{3}$ as the oxidant. In a typical procedure, the mass ratio of CA and pyrrole is $1: 1$, the mole ratio of pyrrole and Ferric chloride hexahydrate is $1: 1$. Pyrrole was firstly dropwise added to the $\mathrm{CA}$ merged in the solution of $\mathrm{FeCl}_{3}$, then the mixture was sonicated several minutes before transferred into a ${ }_{45}$ Teflon-lined stainless steel autoclave (the ratio volume of solution/volume of autoclave is 0.6 ). The autoclave was sealed and maintained at $120{ }^{\circ} \mathrm{C}$ for $12 \mathrm{~h}$. After the reaction was completed, the autoclave was allowed to cool to room temperature. The obtained sample was filtered, washed with 50 deionized water and dehydrate alcohol to remove impurities and excess ions, and dried in air at $60{ }^{\circ} \mathrm{C}$ for $24 \mathrm{~h}$. To obtain the $\mathrm{N}-$ doped carbon materials, the dry gels were calcined at 600,800 , $1000{ }^{\circ} \mathrm{C}$ for 1 hours in $\mathrm{N}_{2}$ atmosphere with ramp heating rate of 3
${ }^{\circ} \mathrm{C} \min ^{-1}$. The obtained samples were designated as $\mathrm{N}-\mathrm{CA}-\mathrm{T}$, 55 where $\mathrm{T}$ represents the carbonaceous temperature.

Characterization: The morphologies of the obtained structures were characterized by Field-emission scanning electron microscope (FE-SEM, JSM7500F) and transmission electron microscopy (TEM) (JEM-2100). X-ray diffraction (XRD) ${ }_{60}$ patterns of samples were measured on a Y-2000 X-ray Diffractometer with copper $\mathrm{K} \alpha$ radiation $(\lambda=1.5406 \AA)$ operating at $40 \mathrm{kV}$ and $40 \mathrm{~mA}$. The Raman measurements were carried out on a Renishaw Microscope System RM2000 equipped with a 50 $\mathrm{mWAr}^{+}$laser at $514.5 \mathrm{~nm}$. Fourier transform infrared spectra ${ }_{65}$ (FTIR) were recorded on a TENSOR 27 FTIR spectrometer (Bruker) in the absorption mode with resolution of $2 \mathrm{~cm}^{-1}$ to identify the surface functional groups of the carbonaceous gels. $\mathrm{N}_{2}$ adsorption isotherms were obtained at $77 \mathrm{~K}$ using a Micromeritics ASAP 2020 system. The samples were degassed 70 at $300{ }^{\circ} \mathrm{C}$ for $10 \mathrm{~h}$ before measurements. Specific surface areas and pore size distributions of the electrode materials were calculated by Brunauer-Emmett-Teller (BET) method. X-ray photoelectron spectroscopy (XPS, XR5 Gun-500 um) was collected using Al K Alpha radiation operated at $150 \mathrm{~W}$ and 15 $75 \mathrm{kV}$. The full survey was taken at $100 \mathrm{eV}$ pass energy with a scan rate of $1 \mathrm{eV} \mathrm{s}^{-1}$.

Electrochemical Measurement: A three-electrode configuration was used to measure the cyclic voltammetry, constant current charge/discharge behavior, and electrochemical impedance 80 spectroscopy. CV, EIS, and chronopotentiometry experiments were performed on a $\mathrm{CHI} 660 \mathrm{D}$ electrochemical workstation at room temperature. The working electrode was prepared by mixing $80 \quad \mathrm{wt} \% \quad \mathrm{~N}-\mathrm{CA}-\mathrm{T}$ composite material, $10 \mathrm{wt} \%$ polytetrafluoroethylene (PTFE, used as a binder, PTFE $60 \mathrm{wt} \%$ ${ }_{85}$ dispersion in $\mathrm{H}_{2} \mathrm{O}$, Sigma Aldrich), and $10 \mathrm{wt} \%$ carbon black. The mixture was spread and pressed onto a nickel foam $(1 \mathrm{~cm} \times 1 \mathrm{~cm})$. After the electrode materials were loaded, the working electrode was pressed and dried in vacuum at $80{ }^{\circ} \mathrm{C}$ for $12 \mathrm{~h}$. The above loaded nickel foam was used as working 90 electrode in a three-electrode system using Pt foil and $\mathrm{Ag} / \mathrm{AgCl}$ as auxiliary and reference electrodes, respectively. The electrolyte used in all of the measurements was a $6 \mathrm{M} \mathrm{KOH}$ solution. The potential range for $\mathrm{CV}$ tests was -1.0 to $0 \mathrm{~V}$, and the scan rate was $5,10,20,50$, and $100 \mathrm{mV} \mathrm{s}^{-1}$. Galvanostatic 95 charge/discharge measurements were done from -1.0 to $0 \mathrm{~V}$ with different current densities at $0.2,0.5,1,2,4$ and $6 \mathrm{~A} \mathrm{~g}^{-1}$. Electrochemical impedance spectroscopy (EIS) measurements were carried out in a frequency range of $0.01 \mathrm{~Hz}$ to $100 \mathrm{KHz}$ with AC amplitude of $5 \mathrm{mV}$.

The specific capacitances obtained from the $\mathrm{CV}$ curves are calculated by the equation $\mathrm{C}=(\Delta \mathrm{S}) /(\mathrm{vmu})$, where $\mathrm{C}$ is the specific capacitance $\left(\mathrm{F} \mathrm{g}^{-1}\right), \Delta \mathrm{S}$ the area of the $\mathrm{CV}$ curves, $\mathrm{u}$ the potential window $(\mathrm{V}), \mathrm{v}$ the scan rate $\left(\mathrm{mV} \mathrm{s}^{-1}\right)$ and $\mathrm{m}$ the mass of the sample used for the electrochemical test (g) excluding the 105 binder and conductive carbon black. The specific capacitance of the electrode material was calculated from the discharge curve according to $\mathrm{C}=\mathrm{I} \Delta \mathrm{t} /(\Delta \mathrm{V} \mathrm{m})$, where $\mathrm{I}$ is the discharge current (A), $\Delta \mathrm{t}$ the discharge time $(\mathrm{s}), \Delta \mathrm{V}$ the voltage change (V) excluding IR drop in the discharge process, and $\mathrm{m}$ the mass of 
the electrode material $(\mathrm{g})$ excluding the binder and conductive carbon black.

\section{Results and discussions}

The experimental sketch of our hydrothermal carbonization 5 (HTC) combining with PPy-nitriding process is illustrated in Scheme 1, in which sugar-based (containing glucose, fructose, and cane sugar et al.) watermelon was used as a renewable starting carbon material and PPy introduced via hydrothermal polymerisation of pyrrole. At the initial synthesis stage, a mild 10 one-step hydrothermal carbonization of watermelon soft tissues was applied to generate monolithic carbonaceous aerogel (CA). This process committed a series of reactions, involving dehydration, polymerization toward polyfurans and carbonization via further intermolecular dehydration. In the second stage, 15 pyrrole was dropped onto the obtained CA and then put it into the solution containing $\mathrm{FeCl}_{3}$ oxidant in a Teflon-lined stainless steel autoclave for hydrothermal polymerization. The collected PPy@CA was further calcined at varying temperatures to obtain $\mathrm{N}$-doped 3D biomass-based porous carbonaceous aerogel.

20

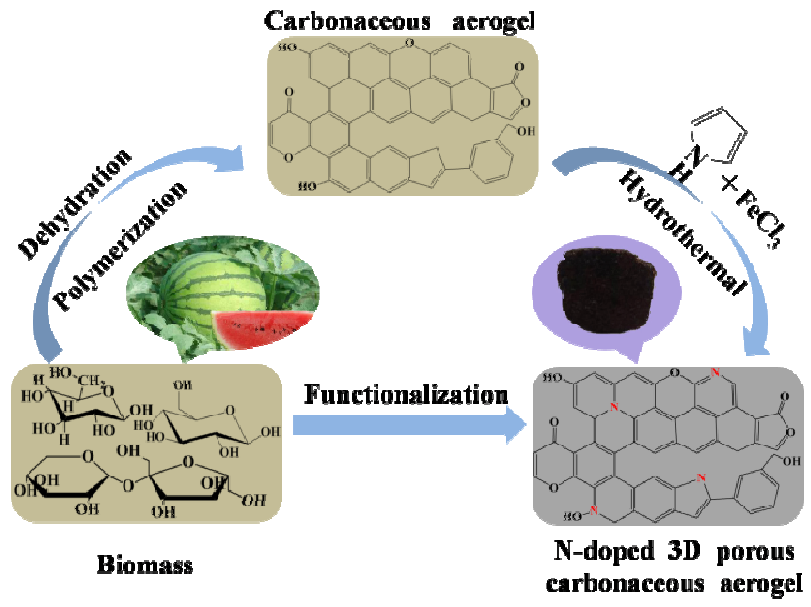

Scheme 1. The schematic strategy for the fabrication of $\mathrm{N}$-doped 3D biomass-based porous carbonaceous aerogel.

25 Fig. 1 (a) and (b) show a sponge-like monolithic of carbonaceous hydrogel (CG) and carbonaceous aerogel (CA) obtained through hydrothermal carbonization without and with freeze-drying, respectively. Scanning electron microscopy (SEM) and transmission electron microscopy (TEM) were used to 30 observe the architecture of $\mathrm{CA}$ and CA-based composite materials. SEM images reveal that the obtained CA consists of carbon nanofibers network cross-linked with carbon nanospheres constituting a 3D porous structure (Fig. 1c). Further hydrothermal treatment of $\mathrm{CA}$ with pyrrole and subsequent 35 freeze-drying (Fig. 1d), the CA was covered with sheet-like PPy generated from in-situ polymerization of pyrrole. It was reported the hydrogen bonding, electrostatic interactions and $\pi-\pi$ bonding between PPy and CA may provide the strong cross-linking sites in the network. ${ }^{27,44}$ Meanwhile, the polymerization of excess Py 40 along normal 3D porous structure leads to partial aggregation of PPy. The PPy@CA was calcined at different temperatures to study the influence of nitriding parameters. Fig. 1(e) shows the
SEM image of N-CA-600, where the PPy scales are completely vanished as compared to the morphology of uncalcined 45 PPy@CA (Fig. 1c). It can be easily concluded that the PPy was introduced into the $\mathrm{C}$ network by thermal treatment and the $\mathrm{C}$ network was nitriding (see XPS section). SEM images of N-CA800 and N-CA-1000 are also shown in Figure S1a, b. The TEM image of N-CA-600, as shown in Fig. 1(f), reveals it possesses ${ }_{50}$ loosely-packed porous architecture.
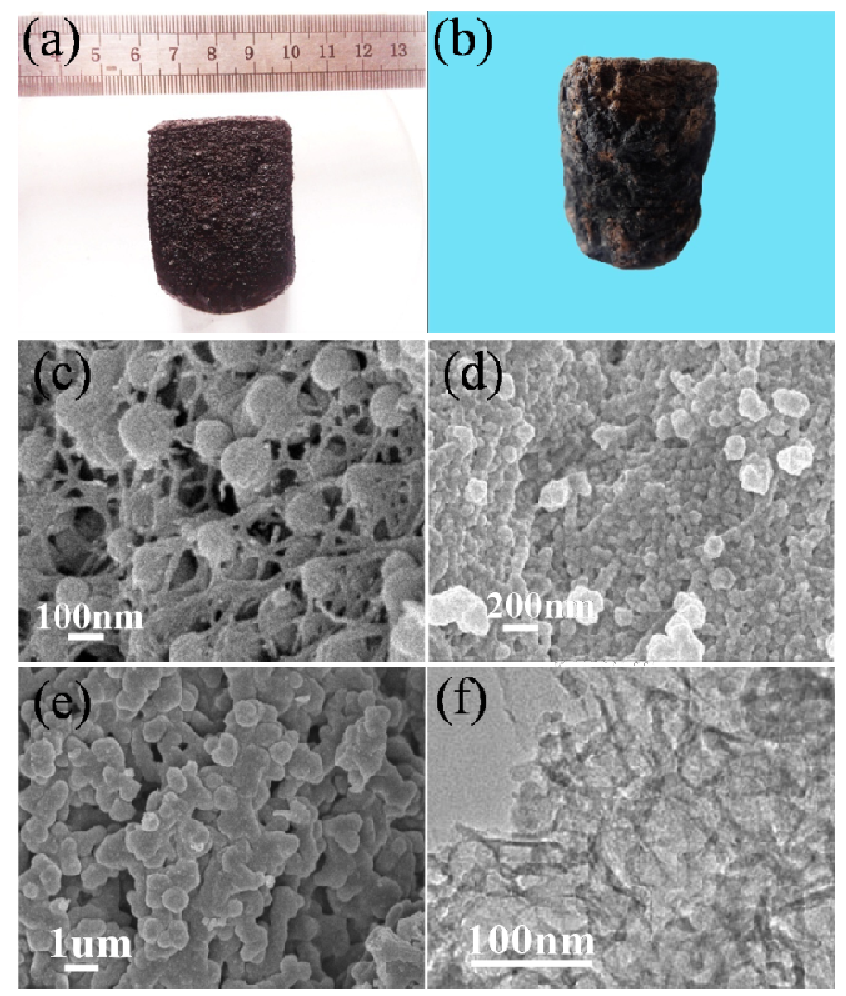

Figure 1. Photographs of monolithic carbonaceous hydrogel (a) and aerogel (b); SEM images of carbonaceous aerogel (c), PPy@CA (d) and N55 CA-600 (e). TEM images of carbonized PPy@CA at $600{ }^{\circ} \mathrm{C}(\mathrm{f})$.

Fig. 2(a) shows the Raman spectra of CA, PPy@CA and NCA-600 samples. Distinguished D band $\left(\sim 1,358 \mathrm{~cm}^{-1}\right)$ and $\mathrm{G}$ band $\left(\sim 1,580 \mathrm{~cm}^{-1}\right)$ are observed in the Raman spectrum of CA. ${ }_{60}$ The $\mathrm{D}$ band can be assigned to defects in the structure while the $\mathrm{G}$ band corresponds to the vibration of $\mathrm{sp}^{2}$ hybridized carbon. ${ }^{11,45}$ The intensity ratio of $\mathrm{D}$ and $\mathrm{G}$ bands $\left(\mathrm{I}_{\mathrm{D}} / \mathrm{I}_{\mathrm{G}}\right)$ has been widely accepted a good index reflecting the extent of structural disorder. ${ }^{11,44}$ The calculated $\mathrm{I}_{\mathrm{D}} / \mathrm{I}_{\mathrm{G}}$ ratio for $\mathrm{CA}$ is 0.3097 , 65 suggesting it was highly graphitized. The PPy@CA nanocomposite shows much stronger Raman spectrum and larger $\mathrm{I}_{\mathrm{D}} / \mathrm{I}_{\mathrm{G}}$ ratio than those of $\mathrm{CA}$, suggesting the presence of PPy entailed significant influence on CA. In addition, to the PPy@CA, the strong characteristic bands at $\sim 1,358 \mathrm{~cm}^{-1}$ and $70 \sim 1,580 \mathrm{~cm}^{-1}$ are also attributed to the ring stretching mode and the $\mathrm{C}=\mathrm{C}$ backbone stretching of $\mathrm{PPy}$, respectively. ${ }^{46,47}$ The Raman spectrum of the N-CA-600 nanocomposite possess relatively stronger D-band, revealing it contains lower degree of graphitic carbon and significant amount of disordered sections or 75 defects. The Raman spectra of PPy@CA as plotted in Fig. 2(b) show elevating calcinations temperature from 600 to $1000{ }^{\circ} \mathrm{C}$ 
results in reduced Raman intensity of D and $\mathrm{G}$ bands. However, the $\mathrm{I}_{\mathrm{D}} / \mathrm{I}_{\mathrm{G}}$ ratio for the samples calcined at 600,800 and $1000{ }^{\circ} \mathrm{C}$ are $0.9176,0.9645,0.9681$, respectively. The increase of $\mathrm{I}_{\mathrm{D}} / \mathrm{I}_{\mathrm{G}}$ ratios as to rising temperature suggests that the temperature is 5 vital to carbonization of the composite materials. While Raman spectra are not able to detail the surface bonding information of the surface functional groups in the composite which can be characterised via FTIR characterisation.
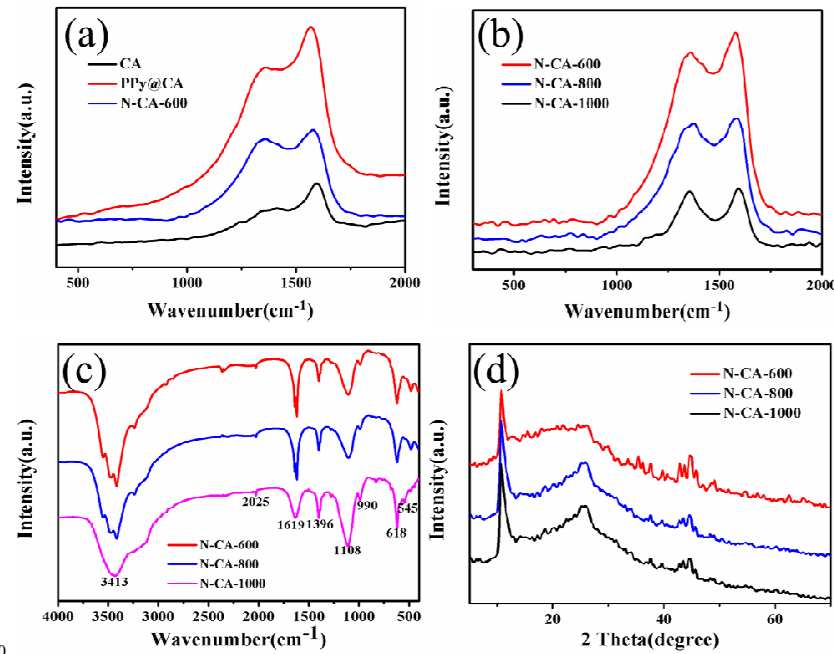

Figure 2. Raman spectra of carbonaceous aerogel, PPy@CA and N-CA600 (a) and N-CA-T. (b); FT-IR spectra (c) and (d) XRD pattern of N-CA-T $\left(\mathrm{T}=600,800,1000^{\circ} \mathrm{C}\right)$.

Fourier transform infrared spectrometry (FTIR) was used to 15 identify surface functional groups of the N-doped carbonaceous aerogel composite materials. As shown in Fig. 2(c), the peaks at ca $3413 \mathrm{~cm}^{-1}$ can be assigned to the N-H symmetric stretching vibration. The existence of $\mathrm{N}$-containing bonds are further confirmed by vibration appearing at ca. $1396 \mathrm{~cm}^{-1} \cdot{ }^{26,48}$ The 20 vibration around $1619 \mathrm{~cm}^{-1}$ can be attributed to $\mathrm{N}-\mathrm{H}$ in-plane deformation vibrations or $\mathrm{C}=\mathrm{C}$ stretching vibration, indicating the presence of aromatic rings or coexistence of $\mathrm{N}-\mathrm{H}$ and $\mathrm{C}=\mathrm{C}$ species. ${ }^{29,43}$ The characteristic absorption band of C-C stretching or breathing vibration of the pyrrole ring at $1108 \mathrm{~cm}^{-1}$ is 25 distinct. $^{29,43}$ Additionally, the peaks at 990 and $618 \mathrm{~cm}^{-1}$ are ascribed to deformation vibration of vinyl $\mathrm{C}-\mathrm{H}$ and $\mathrm{C}-\mathrm{H}$ plane bending vibration, respectively. It is worth noting that increase of carbonization temperature of PPy@CA did not significantly alter the band positions yet raised their intensity of CA (Fig. S2). The 30 presence of PPy was further confirmed by XRD characterization. Fig. 2(d) shows the XRD patterns of the N-doped carbonaceous aerogel N-CA-T composites, where two distinguished peaks due to PPy in the region of $10.7^{\circ}$ and $44.6^{\circ}$ are observed in comparison with that CA (Figure S3).

35 In order to identify the chemical species in the functionalized N-CA-T $\quad\left(\mathrm{T}=600, \quad 800, \quad 1000 \quad{ }^{\circ} \mathrm{C}\right), \quad \mathrm{XPS}$ measurement was carried out and presented in Fig. 3. Remarkable C 1s, N 1s and O 1s peaks are observed in the XPS survey spectra (Fig. 3a, c, e ), revealing the $\mathrm{N}$ species have been $\mathrm{I}_{40}$ introduced into the biomass-derived CA after the hydrothermal polymerization and thermal post-treatments with PPy precursor.
More importantly, the N 1s spectra reveal calcinations amended the surface nitrogen species on the surfaces of PPy@CA composites. The high-resolution N 1s spectrum (Fig. 3b) of N${ }_{45}$ CA-600 evidences the presence of pyridinic-N (N-6, $\left.397.9 \mathrm{eV}\right)$, pyrrolic-N $(\mathrm{N}-5,400.0 \mathrm{eV}) .{ }^{12}$ The fitted to dual peaks of $\mathrm{N} 1 \mathrm{~s}$ spectrum (Fig. 3d) for N-CA-800 show the N-6 (397.9 eV) and $\mathrm{N}-5(400.5 \mathrm{eV})$ peaks are blue shifted, suggesting increase bonding strength. However, their intensity decreases remarkably 50 in comparison to that of N-CA-600, suggesting the concentration of such species were reduced as elevated annealing temperature. After calcination at $1000{ }^{\circ} \mathrm{C}$, the XPS peaks of N-6 and N-5 species almost disappear, suggesting that pyridinic and pyrrole groups are thermally unstable. ${ }^{4,31}$ yet two new peaks (Fig. 3f) turn 55 up at 401.0 and $403.4 \mathrm{eV}$ that are assigned to quaternary-N (N-Q) and $\mathrm{N}$-oxides $(\mathrm{N}-\mathrm{X})$ in pyridine-N group. ${ }^{25,34,49}$ The results demonstrate that the $\mathrm{N}$ atoms within the pentagonal ring of PPy are partly converted into N-6, N-5, N-Q or N-X during the carbonization process. ${ }^{11,41}$ Therefore, the thermal carbonization 60 of PPy@CA represents a good nitriding method to introduce and tune surface N-functional groups, where N-6 bonds with two C atoms at the edges and contributes one $\mathrm{p}$ electron to the $\pi$ system. ${ }^{32} \mathrm{~N}-5$ refers to $\mathrm{N}$ atoms that contribute two $\mathrm{p}$ electrons to the $\pi$ system (inset in Fig. 3b), and N-Q refers to $\mathrm{N}$ atoms that ${ }_{65}$ substitute for $\mathrm{C}$ atoms in the hexagonal ring. Apart from these three common nitrogen types, there are $\mathrm{N}-\mathrm{X}$ bonds in which $\mathrm{N}$ is bonded with two $\mathrm{C}$ atoms and one oxygen atom (inset in Fig. 3f). $\mathrm{N}-\mathrm{X}$ was ever observed in the FTIR of N-graphene, N-carbon nanotubes and $\mathrm{N}$-carbon nanofibers. ${ }^{4,11,24,50}$

70
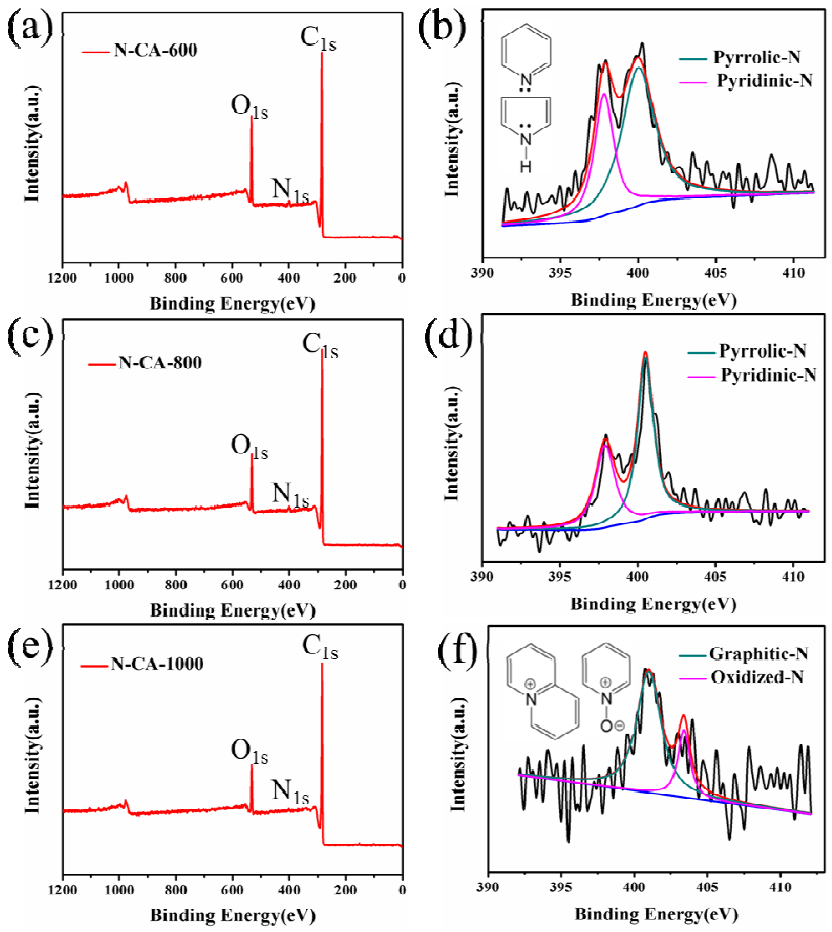

Figure 3. XPS survey scan of the $\mathrm{N}$-doped carbonaceous aerogel composite materials: (a) N-CA-600, (c) N-CA-800, (e) N-CA-1000. Highresolution N1s peaks of (b) N-CA-600, (d) N-CA-800, (f) N-CA-1000.

Table 1 summarised the surface atomic concentrations of $\mathrm{C}$, $\mathrm{O}$, and $\mathrm{N}$ were calculated from the peak areas of corresponding 
XPS spectra. The nitrogen contents of samples N-CA-T $(\mathrm{T}=600$, $800,1000{ }^{\circ} \mathrm{C}$ ) are $2.12,1.04,0.98$ at $\%$, respectively. The nitrogen content in the materials decreases significantly as elevating calcination temperatures, which is in agreement with ${ }_{5}$ FTIR results. The low doping level is mainly associated with high annealing temperature that accelerates the decomposition of $\mathrm{N}$-containing frameworks as well as breaks the $\mathrm{C}-\mathrm{N}$ bonds to release bonded $\mathrm{N}$. It also implies insufficient defect amount was created in the carbon network because doped $\mathrm{N}$ atoms creates 10 structural defects in the carbon material and give rise to more active sites. ${ }^{23,31,32,51}$ XPS results demonstrate that the calcination temperature is a critical factor in determining the relative concentrations of nitrogen species and carbon. Moreover, the accessible $\mathrm{N}$-containing species would provide chemically active 15 sites and facilitate the power density of supercapacitors since $\mathrm{N}$ atoms in heterocyclic ring may influence the spin density and charge distribution of neighbouring $\mathrm{C}$ atoms and then activate the carbon. $^{11,31,51}$
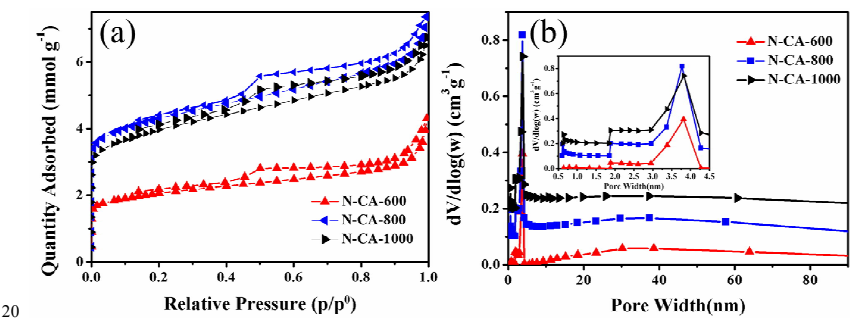

Figure 4. Nitrogen adsorption-desorption isotherms (a), BJH desorption pore-size distribution (b) of N-CA-T $\left(T=600,800,1000{ }^{\circ} \mathrm{C}\right)$. The inset shows the magnified $0.5-4.5 \mathrm{~nm}$ region.

$25 \quad \mathrm{~N}_{2}$ adsorption-desorption measurements were performed to determine the porosity of the N-doped 3D carbonaceous aerogel composites. The textural properties of these materials are summarized in Table 1. As listed in Table 1, the surface area $\left(\mathrm{S}_{\mathrm{BET}}\right)$ of the aerogels increases from 158.3 to $330.4 \mathrm{~m}^{2} \mathrm{~g}^{-1}$ as 30 elevating calcination temperature from 600 to $800{ }^{\circ} \mathrm{C}$, yet falls down to $305.8 \mathrm{~m}^{2} \mathrm{~g}^{-1}$ at $1000{ }^{\circ} \mathrm{C}$. As shown in Fig. 4(a), the $\mathrm{N}$ doped aerogels display II/IV type bi-model isotherm profiles with strong adsorption at low relative pressure, suggesting that micro-, meso- and macropores coexist in the materials. ${ }^{23,31,51}$

${ }_{35}$ Such a hierarchical nanoporous architecture is highly desirable for energy storage and conversion because it allows the fast ion diffusion via shortening the diffusion pathways, where macroporous frameworks may serve as ion-buffering reservoirs, mesoporous walls as ion-highways for fast ion transmission and 40 microporous textures for charge accommodation. ${ }^{12,21,38}$ Fig. 4(b) shows the Barret-Joyner-Halenda (BJH) pore size distribution profiles derived from desorption branches. The sharp peaks centering at $3.7 \mathrm{~nm}$ are observed in all the three $\mathrm{N}$-doped carbon aerogels (inset of Fig. 4b), revealing the mesopores are dominant 45 in the aerogels. The $\mathrm{N}_{2}$ adsorption-desorption characterisation results reveal that the carbonization temperature determines the pore structure of the resulting samples.
Table 1. Physical and electrochemical properties of N-CA-T ( $T=600,800$, $\left.501000^{\circ} \mathrm{C}\right)$.

\begin{tabular}{|c|c|c|c|c|c|c|c|c|}
\hline \multirow[b]{2}{*}{ samples } & \multicolumn{5}{|c|}{ Physical Properties } & \multicolumn{3}{|c|}{ Chemical Properties } \\
\hline & $\begin{array}{c}S_{\mathrm{BET}} \\
\left(\mathrm{m}^{2} \mathrm{~g}^{-1}\right)\end{array}$ & $\begin{array}{c}S_{\text {milero }} \\
\left(\mathrm{m}^{2} \mathrm{~g}^{-1}\right)\end{array}$ & $\begin{array}{c}V_{\text {tot }} \\
\left(\mathrm{cm}^{3} \mathbf{g}^{-1}\right)\end{array}$ & $\begin{array}{c}V_{\text {miera }} \\
\left(\mathrm{cm}^{3} \mathrm{~g}^{-1}\right)\end{array}$ & $\begin{array}{c}\text { Pore } \\
\text { size(nm) }\end{array}$ & $\begin{array}{c}\mathbf{N} \\
\text { (at.\%) }\end{array}$ & $\begin{array}{c}\mathbf{C} \\
\text { (at.\%) }\end{array}$ & $\begin{array}{c}\mathbf{0} \\
(\text { at. \%) }\end{array}$ \\
\hline N-CA-600 & 158.3 & 83.8 & 0.118 & 0.039 & 2.99 & 2.12 & 82.43 & 15.45 \\
\hline N-CA-800 & 330.4 & 185.7 & 0.227 & 0.086 & 2.75 & 1.04 & 87.27 & 11.7 \\
\hline N-CA-1000 & 305.8 & 160.4 & 0.210 & 0.074 & 2.75 & 0.98 & 89.27 & 9.74 \\
\hline
\end{tabular}

Cyclic voltammetry (CV) and galvanostatic charge/discharge in $6 \mathrm{M} \mathrm{KOH}$ aqueous solution are employed to 55 investigate the electrochemical performance of the samples within the potential window between -1.0 and $0 \mathrm{~V}$. Electrochemical performance of CA-600 and N-CA-600 are comparatively shown in Fig. 5. It can be seen from Fig. 5(a) that the CA-600 exhibits small rectangular $\mathrm{CV}$ behaviour ${ }_{60}$ corresponding to low capacitances, whereas the N-CA-600 possesses with nearly rectangular capacitive $\mathrm{CV}$ profile with a few humps thanks to the combination of electric double-layer capacitance and pseudocapacitance. Fig. 5b compares the charge/discharge behaviour of the CA-600 and N-CA-600 ${ }_{65}$ electrodes. The discharging time of N-CA-600 was obviously longer than that of CA-600, indicating that N-CA-600 has a much larger capacitance. It is the doping of $\mathrm{N}$ that provides superior electrochemical performance of N-CA-600 to CA-600 since the doped $\mathrm{N}$ atoms could induce pseudocapacitive 70 behaviour, enhance the surface compatibility with aqueous electrolyte and ensure complete utilization of the exposed surface for charge storage. ${ }^{12,52}$
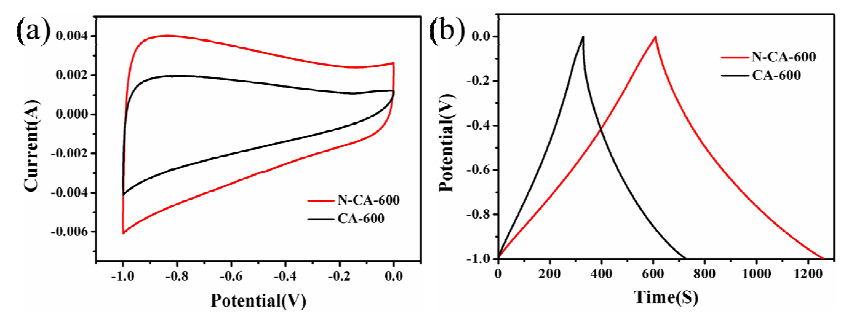

75 Figure 5. (a) Cyclic voltammetry (CV) curves of CA-600 and N-CA-600 electrode in $6 \mathrm{M}$ aqueous $\mathrm{KOH}$ electrolyte at $5 \mathrm{mV} \mathrm{s} \mathrm{s}^{-1}$ scan rate; (b) Charge/discharge curves of the CA-600 and N-CA-600 electrodes, constant current densities: $0.2 \mathrm{~A} \mathrm{~g}^{-1}$.

80 The CV behaviour of PPy@CA electrode materials calcined at different temperature in order to understand the effect of calcination temperature on the electrochemical performance. The specific capacitance of N-CA-T $\left(\mathrm{T}=600,800,1000{ }^{\circ} \mathrm{C}\right)$ electrode against the scan rates of $5 \mathrm{mV} \mathrm{s}^{-1}$ is plotted in Fig. 6(a). The CV 85 curves are approximately rectangular shapes, indicating the $\mathrm{N}$ doped carbon aerogel electrodes own good electrochemical performances. Their insignificant deviation from the ideal rectangular shape may be arisen from the resistance of the electrolyte and the contact resistance between the electrode and 90 the current collector. ${ }^{52,53}$ The N-CA-600 electrode exhibits a high specific capacitance of $281.0 \mathrm{~F} \mathrm{~g}^{-1}$, which is much higher than N-CA-800 $\left(168.9 \mathrm{~F} \mathrm{~g}^{-1}\right)$ and N-CA-1000 $\left(71.6 \mathrm{~F} \mathrm{~g}^{-1}\right)$ at the same scan rate at $5 \mathrm{mV} \mathrm{s}^{-1}$. Fig. 6(b) comparatively shows the calculated specific capacitances at different scan rates of the 95 three samples. Despite enhanced scan rates reduce the 
capacitance of the electrodes, the N-CA-600 electrode shows the best capacitance performance in broad scan rate ranges.

The capacitive behaviours of the three $\mathrm{N}$-doped samples evaluated by the galvanostatic charge-discharge technique at 5 constant current density of $0.2 \mathrm{~A} \mathrm{~g}^{-1}$ are shown in Fig. 6(c). It can be clearly seen that all the curves exhibited symmetric triangles with gradual change of slopes in the potential range from -1.0 to $0 \mathrm{~V}$, suggesting good electric double-layer capacitance performances. The discharging time of the three samples can be 10 readily deduced from the discharge curves. From the discharge curve, the specific capacitance of N-CA-600 is calculated to be 150.6 $\mathrm{F} \mathrm{g} \mathrm{g}^{-1}$ at a current density of $0.2 \mathrm{~A} \mathrm{~g} \mathrm{~g}^{-1}$, while specific capacitance values of N-CA-800 and N-CA-1000 are $101.5 \mathrm{~F} \mathrm{~g}^{-1}$ and $41.5 \mathrm{~F} \mathrm{~g} \mathrm{~g}^{-1}$ respectively. These results verify that the N-CA15600 electrode owns outstanding electrochemical performance.

The interfacial properties of electrodes were recorded using Electrochemical impedance spectroscopy (EIS) carried out in a frequency range from $0.01 \mathrm{~Hz}$ to $100 \mathrm{KHz}$ and the results were presented in Fig. 6(d). The theoretical Nyquist plot of a 20 supercapacitor consists of three regions depending on the frequencies. The semicircular part at higher frequencies corresponds to the electron transfer limited process, and its diameter is equivalent to the Faradic charge transfer resistance $\left(\mathrm{R}_{\mathrm{ct}}\right)$, solution resistance $\left(\mathrm{R}_{\mathrm{s}}\right)$ is the intersection of the curve at ${ }_{25}$ real part $Z^{\prime}$ in the high frequencies range, and the Warburg impedance $(\mathrm{W})$ is the slope of the curves at a low frequencies. Nyquist plot of the N-CA-600 exhibits a smaller diameter of semicircular in high frequency region than N-CA-800 and N-CA1000 , suggesting higher conductivity is achieved in the N-CA${ }_{30} 600$ system. At the same time, the more vertical shape at lower frequencies for N-CA-600 indicates a more capacitive behaviour of the electrode.
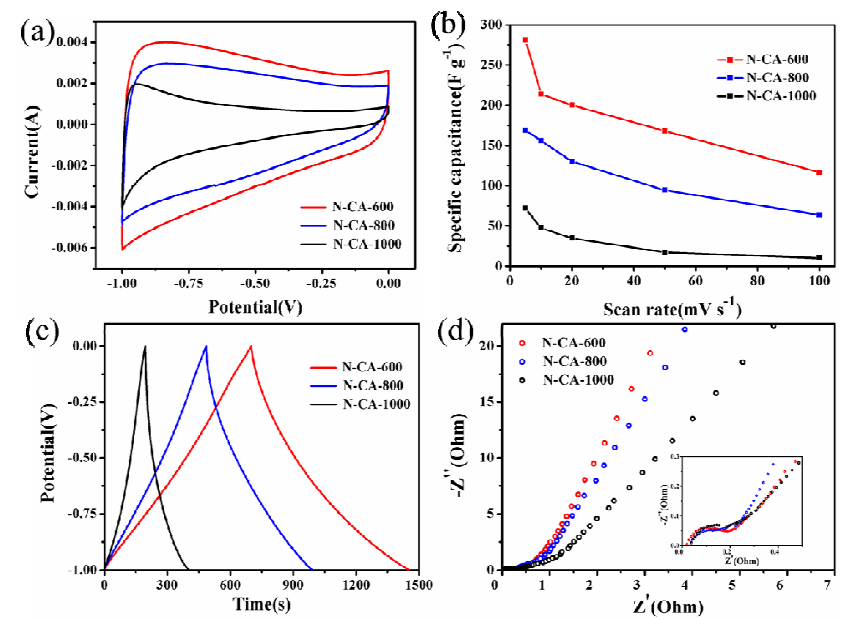

35 Figure 6. (a) $\mathrm{CV}$ curves of N-CA-T electrodes in $6 \mathrm{M}$ aqueous $\mathrm{KOH}$ electrolyte, scan rates: $5 \mathrm{mV} \mathrm{s}^{-1}$; (b) Calculated specific capacitances of $\mathrm{N}$ CA-T electrodes at different scan rates; (c) Charge/discharge curves of $\mathrm{N}$ CA-T electrodes at constant current density of $0.2 \mathrm{~A} \mathrm{~g}^{-1}$; (d) Nyquist plot of N-CA-T, T=600, $800,1000{ }^{\circ} \mathrm{C}$. The inset shows the magnified $0-0.5$ 40 Ohm region.

In electrochemical applications, specific capacitance is normally a linear function of the total surface area, that is the larger the surface area the greater double layer capacitance.
However, the capacitance in nitrogen-functionalized carbon is 45 not following to this rule. This effect was credited to pseudocapacitance due to the faradaic redox reaction of edge $\mathrm{N}$ in the structures derived from pyridine or pyrrole in the carbonaceous materials. Therefore, a higher BET surface area was not always translate to higher performance in 50 electrochemical systems. ${ }^{38}$ The sample N-CA-600 of high specific capacitance may be attributed to its relatively high $\mathrm{N}$ doping level that changes the electron donor/acceptor characteristics of carbon despite that its surface area is only 158.3 $\mathrm{cm}^{2} \mathrm{~g}^{-1}$. This is in agreement to previous studies where the $\mathrm{N}$ ${ }_{55}$ functionalities, i.e. N-6 and N-5, bring about enhance capacitance as a result of existence of pseudocapacitance effect. ${ }^{31,35,36,38,54}$ Nevertheless, N-Q functionalities were found less active than other $\mathrm{N}$-functionalities for supercapacitors. ${ }^{31,51,55}$ From the perspective of binding energy in XPS analysis, it has been 60 convinced that the N-6 should play the dominant role in the capacitance enhancement since it exhibited the largest binding energy. ${ }^{26,32,50}$ Therefore, controlling appropriate $\mathrm{N}$ configuration and concentration can greatly promote the capacitance of $\mathrm{N}$ doped carbonaceous aerogel electrodes.

\section{${ }_{65}$ Conclusions}

In this study, we have demonstrated a feasible, scalable and cost efficient synthesis of 3D N-doped carbonaceous aerogels from sustainable biomass starting products. The fabrication of biomass-based porous $\mathrm{N}$-doped carbonaceous material involves a 70 one-pot hydrothermal synthesis of CA, following with hydrothermally preparation of PPy@CA prior to calcinations that finally introduce $\mathrm{N}$ into the $\mathrm{C}$ network. This preparation methodology offers great flexibility in tailing the nitrogen bonding configurations and surface areas via varying the 75 carbonization temperature. Thanks to the unique feature of the material, the PPy@CA prepared at $600{ }^{\circ} \mathrm{C}$ displays an excellent specific capacitance of $281.0 \mathrm{~F} \mathrm{~g} \mathrm{~g}^{-1}$. We believed that these $\mathrm{N}$ doped porous carbons are highly promising as novel versatile nanomaterials for multi-purpose applications in energy fields, 80 and the synthesis strategy opens a good pathway to employ the abundant and renewable natural resources for manufacturing $\mathrm{N}$ doped porous carbon materials.

\section{Acknowledgements}

We are grateful for the National Natural Science Foundation of ${ }_{85}$ China (No. 51173170, 50955010, 20974102), the financial support from the Innovation Talents Award of Henan Province (114200510019), State Key Laboratory of Chemical Engineering (No. SKL-ChE-13A04), and the Key program of science and technology (121PZDGG213) from Zhengzhou Bureau of science 90 and technology.

\section{Notes and references}

${ }^{a}$ College of Materials Science and Engineering, Zhengzhou University, Zhengzhou 450052, China. fax: +86 371 67767827; Tel.: +86 371 67767827;E-mail:qunxu@zzu.edu.cn;

$95{ }^{b}$ Energy Technology Group, Faculty of Engineering and the Environment, University of Southampton, Southampton, SO17 1BJ, UK. Tel: +44-(0)23 80594893, Email: z.jiang@soton.ox.ac.uk 
$\dagger$ Electronic Supplementary Information (ESI) available: SEM images of N-CA-800 (d) and N-CA-1000, FTIR of carbonaceous aerogel, XRD of carbonaceous aerogel. See DOI: 10.1039/b000000x/

5 1. C. Falco, N. Baccile and M. M. Titirici. Green Chem., 2011, 13, 3273-3281.

2. M. M. Titirici, R. J. White, C. Falcoa and M. Sevilla. Energy Environ. Sci., 2012, 5, 6769-6822.

3. J. Zhang, Y. Yu, L. Liu and Y. Wu. Nanoscale., 2013, 5, $10 \quad 3052-3057$.

4. L. F. Chen, X. D. Zhang, H. W. Liang, M. G. Kong, Q. F. Guan, P. Chen, Zh. Y. Wu, and Sh. H. Yu. Synthesis of ACS Nano., 2012, 6, 7092-7102.

5. L. Zhao, L. Zh. Fan, M. Q. Zhou, H. Guan, S. Y. Qiao, M. 15 Antonietti, and M. M. Titirici. Adv. Mater., 2010, 22, 5202 5206.

6. L. L. Zhang, R. Zhou and X. S. Zhao. J. Mater. Chem., 2010, 20, 5983-5992.

7. B. G. Choi, M. H. Yang, W. H. Hong, J. W. Choi, and Y. S. 20 Huh. ACS Nano., 2012, 5, 4020-4028.

8. D. N. Futaba, K. Hata, T. Yamada, T. Hiraoka, etc. Nat. Mater., 2006, 5, 987-994.

9. K. H. An, W. S. Kim, Y. S. Park, J. M. Moon, D. J. Bae, S. C. Lim, Y. S. Lee, Y. H. Lee. Nano Lett., 2012, 12, 38033807.

10. M. Sevilla, R. Mokaya and A. B. Fuertes. Energy Environ. Sci., 2011, 4, 2930-2936.

11. F. Su, C. K. Poh, J. S. Chen, G. Xu, D. Wang, Q. Li, J. Lin, X. W. Lou. Energy Environ. Sci., 2011, 4, 717-724.

30 12. L. Qie, W. M. Chen, H. H. Xu, X. Q. Xiong, Y. Jiang, F. Zou, X. L. Hu, Y. Xin, Zh. L. Zhang and Y. H. Huang. Energy Environ. Sci., 2013, 6, 2497-2504.

13. Y. M. He, W. J. Chen, X. D. Li, et al. ACS Nano., 2013, 7, 174-182.

35 14. W. J. Chen, Y. M. He, X. D. Li, et al. Nanoscale., 2013, 5, 11733-11741.

15. Y. M. He, W. J. Chen, J. Y. Zhou, et al. ACS Appl. Mater. Interfaces., 2014, 6, 210-218.

16. X. Y. Chen, Ch. Chen, Zh. J. Zhang, D. H. Xie, X. Deng, J.

40 W. Liu. Journal of Power Sources., 2013, 230, 50-58.

17. H. L. Guo, Q. M. Gao. Journal of Power Sources., 2009, 186, 551-556.

18. M. M. Titirici and M. Antonietti. Chem. Soc. Rev., 2010, 39,103-116.

45 19. N. Brun, C. A. Garcia-Gonzalez, I. Smirnova and M. M. Titirici. $R S C A d v .$, 2013, 3, 17088-17096.

20. B. Hu, Sh. H. Yu, K. Wang, L. Liu and X. W. Xu. Dalton Trans., 2008, 5414-5423.

21. R. J. White, V. Budarin, R. Luque, J. H. Clark and D. J.

50 Macquarrie. Chem. Soc. Rev., 2009, 38, 3401-3418.

22. X. L. Wu, T. Wen, H. L. Guo, et al. ACS Nano., 2013, 7, 3589-3597.

23. J. Wei, D. D. Zhou, Zh. K. Sun, Y. H. Deng, Y. Y. Xia, and D. Y. Zhao. Adv. Funct. Mater., 2013, 23, 2322-2328.

55 24. B. You, L. L. Wang, L. Yao and J. Yang. Chem. Commun., 2013, 49, 5016-5018.

25. H. M. Jeong, J. W. Lee, W. H. Shin, Y. J. Choi, H. J. Shin, J. K. Kang, and J. W. Choi. Nano Lett., 2011, 11, 2472-2477.

26. Sh. Y. Gao, H. Fan, Y. L. Chen, L. Li, Y. Bando, D. Golberg. $60 \quad$ Nano Energy., 2013, 1-10.

27. Y. H. Lu, F. Zhang, T. F. Zhang, K. Leng, L. Zhang, X. Yang, Y. F. Ma, Y. Huang, M. J. Zhang, Y. Sh. Chen. Carbon., 2013, 63, 508-516.
28. J. P. Paraknowitsch and A. Thomas. Energy Environ. Sci., 2013, 6, 2839-2855.

29. R. J. White, N. Yoshizawa, M. Antonietti and M. M. Titirici. Green Chem., 2011, 13, 2428-2434.

30. R. Lv, Q. Li, A. R. Botello-Mendez, etc. Scientific Reports., 2012, 2,1-8.

70 31. Y. W. Zhang, J. Ge, L. Wang, D. H. Wang, F. Ding, X. M. Tao \& W. Chen. Scientific Reports., 2013, 1-8.

32. H. B. Wang, T. Maiyalagan, and X. Wang. ACS Catal., 2012, 2, 781-794.

33. R. Czerw, M. Terrones, J. C. Charlier, etc. Nano Lett., 2001., 1, 457-460.

34. M. Sevilla, L. H. Yu, T. P. Fellinger, A. B. Fuertes and M. M. Titirici. RSC $A d v$, 2013, 3, 9904-9910.

35. B. Xu, D. F. Zheng, M. Q. Jia, G. P. Cao, Y. Sh. Yang. Electrochimica Acta., 2013, 98, 176-182.

${ }_{80} 36$. B. Xu, Sh. Sh. Hou, G. P. Cao, F. Wu and Y. Sh. Yang. J. Mater. Chem., 2012, 22, 19088-19093.

37. B. Xu, H. D, M. Chu, G.P. Cao and Y. Sh. Yang. J. Mater. Chem. A, 2013, 1, 4565-4570.

38. S. Shrestha and W. E. Mustain. Journal of The Electrochemical Society., 2010, 157, B1665-B1672.

39. Ch. X. Guo, N. Li, L. L. Ji, etc. Journal of Power Sources, 2014, 247, 660-666.

40. A. H. Lu, A. Kiefer, W. Schmidt, and F. Schuth. Chem. Mater., 2004, 16, 100-103.

90 41. G. C. Marjanovic, I. Pasti, N. Gavrilov, A. Janosevic, S. Mentus. Chemical Papers., 2013, 67, 781-813.

42. W. Li, D. Chen, Z. Li, Y. Shi, Y. Wan, G. Wang, Z. Jiang, D. Zhao. Carbon., 2007, 45, 1757-1763.

43. V. Chandra, S. U. Yu, S. H. Kim, Y. S. Yoon, D. Y. Kim, A. 95 H. Kwon, M. Meyyappan and K. S. Kim. Chem. Commun., 2012, 48, 735-737.

44. J. M. Gu, W. S. Kim, Y. K. Hwang, S. Huh. Carbon., 2013, 56, 208-217.

45. Y. M. Tan, Ch. F. Xu, G. X. Chen, etc. ACS Appl. Mater. Interfaces., 2013, 5, 2241-2248.

46. Y. S. Lim, Y. P. Tan, H. N. Lim, N. M. Huang, W. T. Tan. J Polym Res., 2013, 20, 1-10.

47. V. Chandra, and K. S. Kim. Chem. Commun., 2011, 47, 3942-3944.

105 48. R. J. White, M. Antonietti and M. M. Titirici. J. Mater. Chem., 2009, 19, 8645-8650.

49. T. V. Vernitskaya, O. N. Efimov. Russian Chemical Reviews., 1997, 66, 443-457.

50. X. Li, H. Wang, J. T. Robinson, H. Sanchez, G. Diankov, H. 110 Dai. J. Am. Chem. Soc., 2009, 131, 15939-15944.

51. Zh. Li, Zh. W. Xu, X. H. Tan, H. L. Wang, C. M. B. Holt, T. Stephenson, B. C. Olsen and D. Mitlin. Energy Environ. Sci., 2013, 6, 871-878.

52. X. Y. Chen, Ch. Chen, Zh. J. Zhang, D. H. Xie, and X. Deng. Ind. Eng. Chem. Res., 2013, 52, 10181-10188.

53. W. C. Li, G. Reichenauer, J. Fricke. Carbon., 2002, 40, 2955-2959.

54. X. Yang, D. Wu, X. Chen, R. Fu. J. Phys. Chem. C., 2010, 114, 8581-8586.

120 55. C. O. Ania, V. Khomenko, E. Raymundo-Pinero, J. B. Parra and F. Beguin, Adv. Funct. Mater., 2007, 17,1828-1836. 


\section{Biomass-derived Three-dimensional Porous N-doped Carbonaceous Aerogel for Efficient Supercapacitor Electrodes}

Yumei Ren ${ }^{\mathrm{a}}$, Jianmin Zhang ${ }^{\mathrm{a}}$, Qun Xua*, Zhimin Chen ${ }^{\mathrm{a}}$, Daoyuan Yang ${ }^{\mathrm{a}}$, Bo Wang ${ }^{\mathrm{a}}$, Zheng Jiang ${ }^{\mathrm{a}, \mathbf{b}^{*}}$
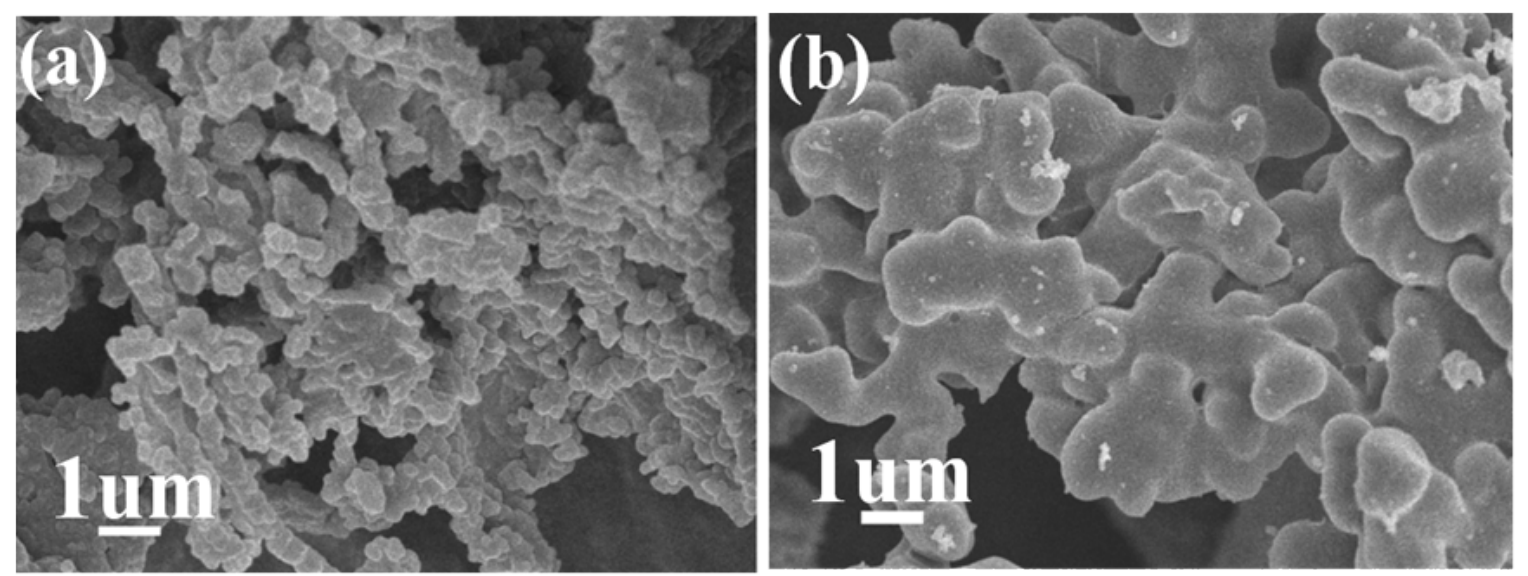

Figure S1. SEM images of N-CA-800 (d) and N-CA-1000.

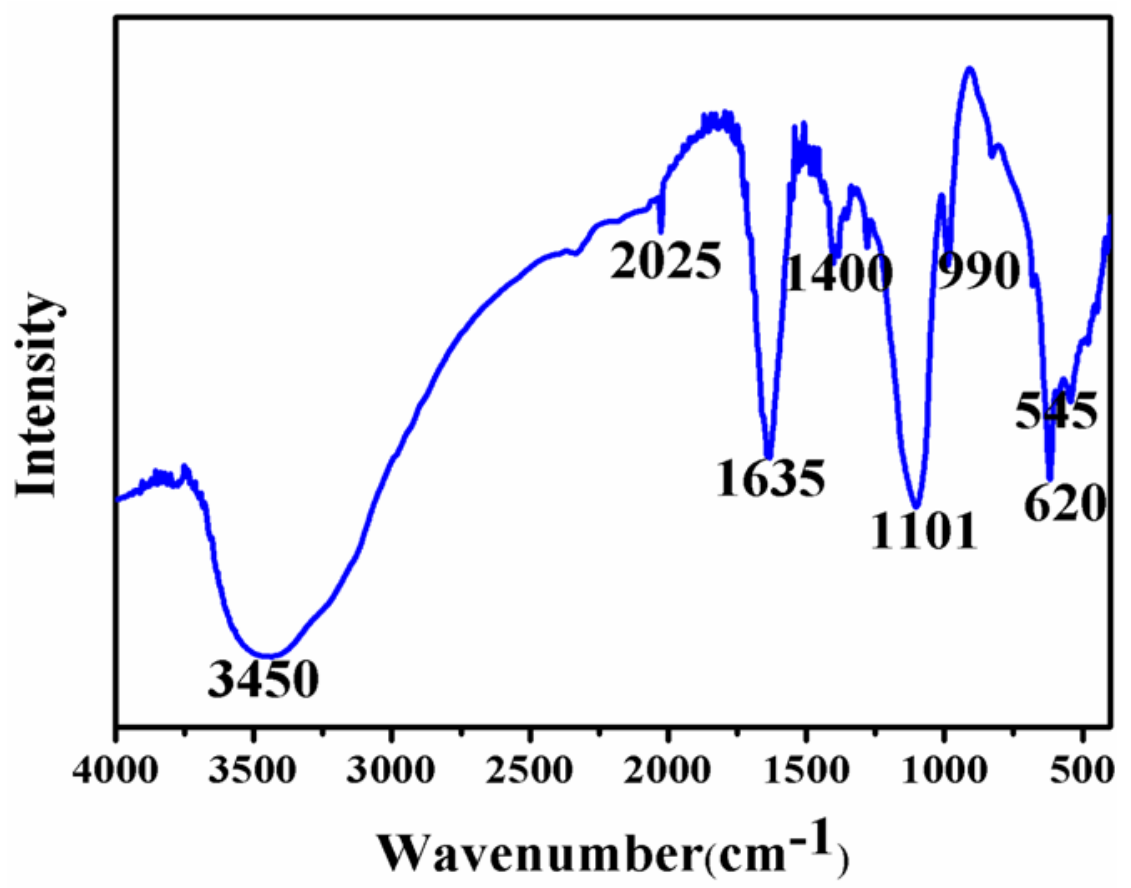

Figure S2. FTIR of carbonaceous aerogel. 


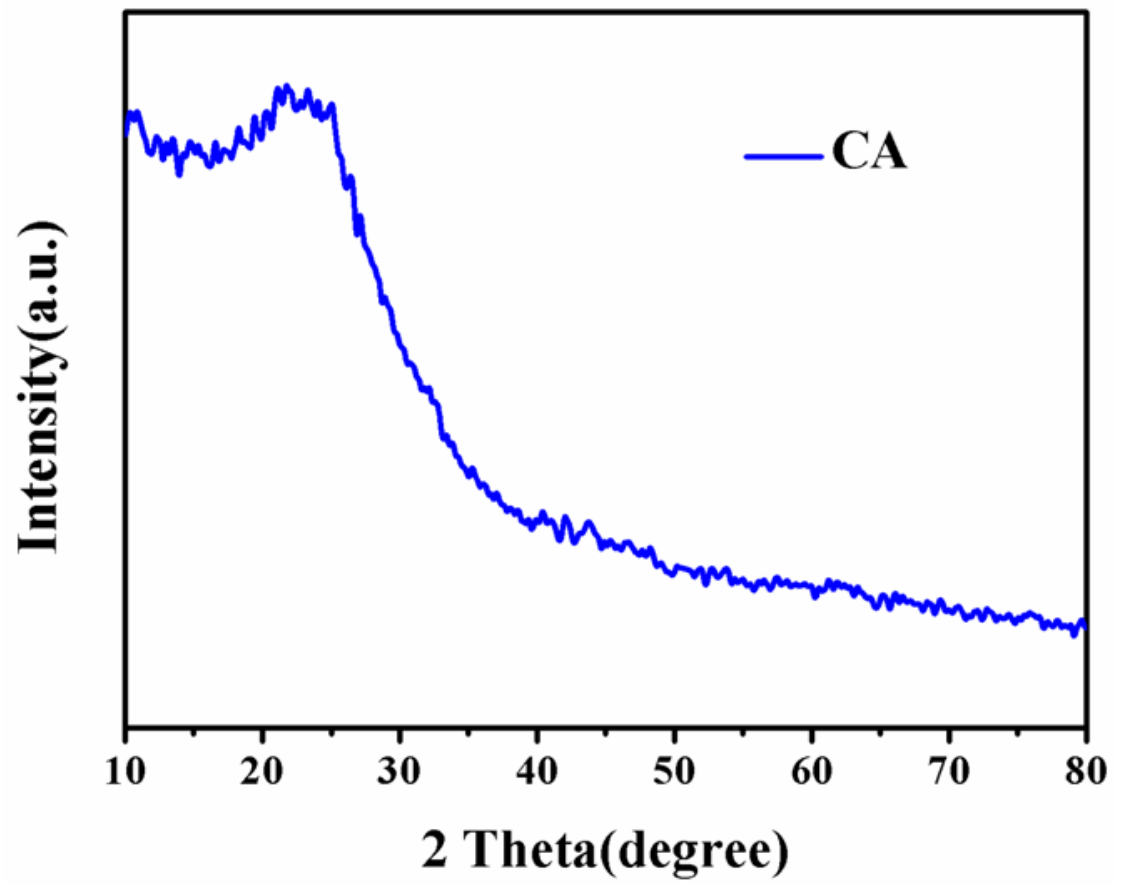

Figure S3. XRD of carbonaceous aerogel. 